committee is formed in Great Britain ?) For early Post-Glacial times the evidence is less intricate, but Dr. Movius's lucid exposition of the Litorina ("25-foot") raised beach is very welcome, and leads him naturally to the subject of the land-bridges and the human migration into Ireland from Britain. All this will be read by natural science workers with interest, and no doubt with appropriate criticism; but it is no less important for the prehistorian, in that the initial Irish Stone Age gives us no 'classic industries' which can be used as dating-fossils on a received typological basis, but itself requires dating-ańd by means that only a natural chronology can supply.

This Dr. Movius has seen to. On to the natural chronology summarized in his Table 6, his excavations have enabled the Irish Stone Age cultures to be projected. They are confined to the north-east, where alone flint for their tools abounded. The earliest station is the site near Tombe Bridge on Lough Neagh, sealed below Late Boreal-Early Atlantic peat, and material of the same initial culture is present in secondary position, preceding the maximum Litorina submergence of Atlantic times, in three coastal sites within varying distances of Larne, whence the cultures are to be known as 'Larnian'. To the Early Larnian succeeds the Late Larnian of the overlying deposits here and elsewhere along the coast; and after that the story continues into the 'Neolithic' Age which came in with the Sub-Boreal period towards 2000 B.c., and beyond the limits of this book.

Who and what were the Larnian people? They were fishermen, hunters, and food-collectors, like their 'Obanian' counterparts of south-west Scotland, and the author's analytical and comparative study of their material culture shows them to have been descendants of the final Upper Palæolithic remnant who had crossed over from Great Britain well back in the Boreal period. Little touched (owing to the ensuing Litorina submergence) by external Mesolithic influence, they lived in a Mesolithic fashion of their own, developed in response to their secluded natural environment. Neolithic and later colonists pushed them in part into the interior, but they and their ancient food-gathering economy came to no abrupt end. In fact, they have demonstrably lived on as a basic stock among the Irish people to this day.

C. F. C. Hawkes.

\section{SCABIES AND ITS TREATMENT}

\section{Scabies}

By Dr. Kenneth Mellanby. (Oxford War Manuals.) Pp. xi+81. (London: Oxford University Press, 1943.) 5s. net.

CCABIES is at present a very important factor in $\checkmark$ both civil and military life. The itch is the commonest skin disease and, paradoxically, the one least recognized by the average medical man. War has been blamed for increases in the amount of scabies in Great Britain, but Dr. Mellanby doubts this and produces figures to show that there was already an increase in the scabies rate in the country between 1935 and 1939. He puts the present infestation rate at about 2 per cent of the population, rising to 5 per cent in some areas.

There is an excellent illustrated description of the life-history of Sarcoptes scabiei and instructions in the art of searching for the mite and extracting it for examination. Counts of live adult females on patients have revealed that the mean parasite-rate is astonishingly low, $11 \cdot 3$ per case, in spite of the widespread distribution of lesions. In only 3 per cent of cases were more than fifty parasites discovered.

It is confirmed that the chief mode of spread in adults is by close contact in warm conditions, so that a high percentage of cases come into the category of venereal infections. Bedding and fomites generally are not considered to be of real importance in spread, and Dr. Mellanby is of the opinion that dis-infestation of the clothing and bedding of cases after treatment is largely a waste of time, since any parasites therein are destroyed by the parasiticide used. This view has not yet found universal acceptance.

For treatment, sulphur ointment, Marcussen's ointment, mitigal and benzyl benzoate are ranked about equal for effective 24-hour treatment. The methods of treatment are described and the preparation of benzyl benzoate emulsions is included. Some illusions will be destroyed in the statement that scabies can be cured without the time-honoured baths and scrubbing, and in twenty-four hours at that.

This little book is the outcome of long and, as the reviewer knows, painstaking research on a large number of civil and service patients. The whole subject is completely covered and admirably condensed into an hour or two's easy reading.

\section{VALVE TECHNIQUE IN SUBATOMIC RESEARCH}

\section{Electrical Counting}

With Special Reference to Counting Alpha and Beta Particles. By Dr. W. B. Lewis. Pp. vii +144. (Cambridge : At the University Press, 1942.) 10s. 6d. net.

TNVESTIGATIONS on radioactivity and cosmic radiation often require the detection of fast particles or the determination of their ionization. Ionization chambers and Geiger-Müller counters are used for these purposes; but the very small electric quantities obtained directly make high amplification desirable.

Research workers will welcome Dr. Lewis's book covering many aspects of valve technique in recording or observing fast particles. Among many other problems the book deals with the design of linear amplifiers suitable for the measurement of the ionization of $\alpha$-particles. A survey is given of the various types of recorders suitable for high input-rates. A scale-of-ten circuit is described which has the advantage of being 'all electric', that is, it avoids the use of a mechanical recorder altogether. The Rossi coincidence circuit is described, and methods are discussed for obtaining high resolving power coincidence circuits.

The book deals only with material which was available before the outbreak of war. This is regrettable as the illuminating investigations on the discharge mechanism of Geiger-Müller counters carried out since are not dealt with.

In our experience the excessive precautions recommended for the use of Geiger-Müller counters (see p. 102) are rather exaggerated.

The presentation of the book is somewhat sketchy. Details might have been left out to make room for a more thorough discussion of some important points, such as the limits of resolving power of simple coincidence circuits or the properties of multivibrator circuits.
L. JÁNOSSY. 